\title{
A TREATMENT DILEMMA CONCERNING IMMUNOSUPPRESSANT USE: A CASE REPORT
}

\author{
MADATHIL SHINU MERY IYPE ${ }^{1}$, AKHILESH KUNOOR ${ }^{2}$, ANILA KN ${ }^{1 *}$
}

${ }^{1}$ Department of Pharmacy Practice, Amrita School of Pharmacy, Kochi, Amrita Vishwa Vidyapeetham, Amrita University, India.

${ }^{2}$ Department of Pulmonary Medicine, Amrita School of Medicine, Kochi, Amrita Vishwa Vidyapeetham, Amrita University, India. Email: anilakn@aims.amrita.edu

Received: 04 April 2017, Revised and Accepted: 27 June 2017

\begin{abstract}
Immunosuppressants including corticosteroids (prednisolone $>15 \mathrm{mg} /$ day) are responsible for an increased risk of susceptibility to infections (especially pneumonia, tuberculosis [TB] including extra pulmonary TB), an important safety concern when providing immunosuppressive therapy. Anti-TB treatment (ATT) is medicines used to treat tuberculosis, an infectious disease which can affect lungs and other organs. Isoniazid, rifampicin, and pyrazinamide are known to cause ATT induced hepatitis. The prevalence of immunosuppressant induced TB and pyrazinamide induced hepatotoxicity during treatment for active TB ranges to about $0.6 \%-1 \%$ and $<1 \%$, respectively. Here, we illustrate a typical case report of a 61 -year-old woman who is a known case of interstitial lung disease and developed TB arthritis following therapy with the long-term use of immunosuppressants (prednisolone, azathioprine, leflunomide, and sulfasalazine). ATT regimen was started for TB arthritis which was later modified along with addition of liver protectant due to the development of hepatotoxicity. The causality of both the adverse drug reactions was confirmed to be probable via NARANJO causality assessment scale. This case highlights the incidence of infectious complications like TB which may be expected to be encountered more frequently in the future due to the increasing use of immunosuppressants for the treatment of allergic and inflammatory disorders.
\end{abstract}

Keywords: Immunosuppressants, Tuberculosis arthritis, Anti-tuberculosis treatment, Interstitial lung disease, Hepatitis.

(C) 2017 The Authors. Published by Innovare Academic Sciences Pvt Ltd. This is an open access article under the CC BY license (http://creativecommons. org/licenses/by/4. 0/) DOI: http://dx.doi.org/10.22159/ajpcr.2017.v10i10.18865

\section{INTRODUCTION}

Immunosuppressive therapy (IMT) is considered the cornerstone of the treatment for gastrointestinal diseases and in the post-transplantation setting. Long-term use of these immunosuppressants [1] can compromise the immune system. The inflammation in interstitial lung disease (ILD) is being treated with steroids (e.g.,: Prednisolone) and other immunosuppressants conventionally (e.g.,: Azathioprine, mofetil or cytoxan) [2] which may increase the chance of developing severe and opportunistic infections (especially pneumonia and tuberculosis [TB] including extra pulmonary TB), osteoporosis (weakening of bones), etc., especially by the long-term use in combination with steroids (prednisolone $>15 \mathrm{mg} /$ day) [3-5]. The overall rate of steroid associated infectious complications was found to be $12.7 \%$ in those randomly allocated to corticosteroids compared with $8 \%$ in those receiving placebo in a meta-analysis of pooled data from controlled clinical trials which comprised 4198 patients with various diseases. Hospital mortality rate due to infections associated with IMT was found to be $78 \%$ in another study. In a study of controlled trial with 100 patients having gastroenterological disorders, the odds ratio for opportunistic infections was found to be $>4.4$ when the treatment was combined with infliximab, corticosteroids, and azathioprine [6]. In addition, the prevalence of miliary TB in malignant disease is 3 times higher than in general population, and its mortality rate is about $25-30 \%$ in adults. Extra spinal TB osteomyelitis is rare and comprises about $2-3 \%$ of all cases of osteoarticular TB; with the hip and knee joints being the most common following spinal involvement [2]. TB affecting the ulna is uncommon but is found to be more common in diaphysis. As per the guidelines of the American Thoracic Society for TB, in patients undergoing long-term high doses of steroid therapy over a month must be considered for prophylactic anti-TB medication to counter the serious toxicity that steroids may induce. Patients diagnosed with TB are usually treated with first line anti-TB treatment (ATT), major side effects of which can cause significant morbidity and compromise treatment regimens for TB [7]. Here, we present a case which focusses on the important recognition of risk factors, monitoring for clinical course and laboratory results and patient education so as to curb the occurrence of untoward reactions which may thus result in a prescription cascade.

\section{CASE REPORT}

A 61-year-old female patient was referred from a local hospital with features of ILD. She was on Wysolone $20 \mathrm{mg}$ OD since 5 years. On evaluation, RA factor was found to be positive and was added on hydroxychloroquine $200 \mathrm{mg}$ OD, leflunomide (Lefno) $20 \mathrm{mg}$ OD, and azathioprine (Azoran) $50 \mathrm{mg}$ BD. She, however, started taking half tablet of $50 \mathrm{mg}$ Azoran due to excessive tiredness and wrist joint pain; without any medical advice. The patient was presented with swelling in the right wrist joint after approximately 3 years of taking multiple immunosuppressants, which gradually increased in size since the past 10 months with gradual waxing and waning. Swelling was associated with pain which was insidious in onset and gradually increasing with exacerbation since the past 5 months, with associated restriction of movements. As the swelling and pain in the wrist joint worsened, the patient was made to undergo a synovial biopsy, magnetic resonance imaging, and smear acid-fast bacilli from wrist joint which confirmed TB. The worsening swelling and pain in wrist joint stressed the need to start Rituximab, but the plan was put on hold owing to deterioration of TB. She was started on four drug ATT regimen following which her liver function tests (LFT) values increased three-fold higher than the normal level, resulting in hepatitis. Initially, ATT was stopped completely and sequentially added after serial monitoring of LFT. Due to deterioration of TB in wrist joint, immunosuppressants including leflunomide and azathioprine had to be stopped. As per clinicoradiological and functional response, steroid dose was tapered and stopped. Due to worsening liver enzymes, pyrazinamide $1250 \mathrm{mg}$ OD was replaced with levofloxacin $750 \mathrm{mg}$ OD and continued ATT as per standard guidelines. The patient was taken up for wound debridement and arthrodesis of the right wrist joint and was started on adequate analgesics (Ultracet $\mathrm{BD}$ which is a combination of tramadol $37.5 \mathrm{mg}$ and acetaminophen $325 \mathrm{mg}$ ) and given limb elevation. The supportive measures and appropriate treatment provided, thus, resulted in complete resolution of the patient's symptoms. 
Table 1: Patient profile during hospital stay

\begin{tabular}{|c|c|c|c|c|c|c|c|}
\hline Case & $\begin{array}{l}\text { Age } \\
\text { (years) }\end{array}$ & Sex & Diagnosis & Immunosuppressant drugs & $\begin{array}{l}\text { ATT medications } \\
\text { (based on weight: } \\
56.1 \mathrm{~kg} \text { ) }\end{array}$ & Tests to confirm TB & $\begin{array}{l}\text { Tests to confirm } \\
\text { hepatitis }\end{array}$ \\
\hline 1 & 61 & $\mathrm{~F}$ & $\begin{array}{l}\text { ТВ } \\
\text { arthritis }\end{array}$ & $\begin{array}{l}\text { Prednisolone } 20 \mathrm{mg} \\
\text { OD (gradually tapered up to } \\
2.5 \mathrm{mg} \text { ), azathioprine } 50 \mathrm{mg} \\
\text { BD, hydrochlorothiazide } \\
200 \mathrm{mg} \text { OD, leflunomide } \\
20 \mathrm{mg} \text { OD }\end{array}$ & $\begin{array}{l}\text { Isoniazid } 300 \mathrm{mg} \mathrm{OD} \text {, } \\
\text { rifampicin } 450 \mathrm{mg} \\
\text { OD, pyrazinamide } \\
1250 \mathrm{mg} \text { OD (replaced } \\
\text { to levofloxacin } \\
750 \mathrm{mg} \text { OD), } \\
\text { ethambutol } 1200 \mathrm{mg}\end{array}$ & $\begin{array}{l}\text { X-ray (right wrist): Gross } \\
\text { destruction. MRI (right } \\
\text { wrist): Moderate to } \\
\text { severe erosive synovial } \\
\text { arthritis involving the } \\
\text { right wrist joint. Synovial } \\
\text { biopsy culture (right wrist } \\
\text { joint): Granulomatous } \\
\text { inflammation suggesting } \\
\text { of TB. Synovial } \\
\text { fluid (smear AFB/TB): } \\
\text { Positive }\end{array}$ & $\begin{array}{l}\text { SGOT: } 153 \text { (normal } \\
\text { value: } 5-45 \text { IU/L) } \\
\text { SGPT: } 99(\text { normal } \\
\text { value: } 5-35 \text { IU/L) }\end{array}$ \\
\hline
\end{tabular}

AFB: Acid-fast bacilli, MRI: Magnetic resonance imaging, ATT: Anti-tuberculosis treatment, TB: Tuberculosis, SGPT: Serum glutamate-pyruvate transaminase, SGOT: Serum glutamic oxaloacetic transaminase

\section{DISCUSSION}

Table 1 shows the clinical profile of our patient including her demographic details, medical condition, the drugs prescribed (immunosuppressant and ATT medications), and the laboratory tests carried out to confirm TB and hepatitis.

Fig. 1 depicts the soft tissue lesion associated with fusion of carpal bone with the involvement of ulnar head with subchondral sclerosis and cystic changes.

Fig. 2 implies the increase in serum glutamate-pyruvate transaminase and serum glutamic oxaloacetic transaminase levels by about twice its normal levels with the inclusion of pyrazinamide in the ATT regimen.

This case shows a causality score of 8 for TB arthritis and 5 for hepatitis using NARANJO probability scale and causality of both the adverse drug reactions were found to be probable.

The prevalence of immunosuppressant induced TB and pyrazinamide induced hepatotoxicity during treatment for TB ranges to about $0.6-1 \%$ and $<1 \%$, respectively, according to recent meta-analysis studies [8]. TB (mycobacterium tuberculosis) is a common infection associated to immunosuppressant therapy involving the treatment with corticosteroids, azathioprine, 6-mercaptopurine, methotrexate, cyclosporine, and infliximab [9]. Isoniazid (INH) [10], rifampicin, and pyrazinamide are first-line ATT drugs which cause drug induced hepatotoxicity. Acetyl hydrazine, a metabolite of INH is responsible for liver damage. Rifampicin is stated to cause transient elevation in liver enzymes within first 8 weeks of therapy in $10-15 \%$ patients but causes hepatotoxicity in $<1 \%$. Pyrazinamide induced hepatotoxicity is dose-related and can occur at any time of therapy, also known to cause fulminant hepatitis. As per a recent review on current treatment modalities for TB, the individual therapeutic regimen for TB must be resolved in view of the current strategies available [11]. If possible immunosuppressant should be stopped or withheld or should be given in the lowest possible dose after assessing the patient's clinical condition as per American College of Rheumatology guidelines [12]. Hepatotoxic drugs should be stopped if LFT increases three-fold higher than normal range and can be re-introduced sequentially in the order:

$\mathrm{INH} \rightarrow$ Rifampicin $\rightarrow$ Pyrazinamide

\section{CONCLUSION}

This case highlights the incidence of infectious complications like TB which may be expected to be encountered more frequently in the future due to the increasing use of immunosuppressants for the treatment of allergic and inflammatory diseases. Patients on ATT should be given proper counseling before starting the therapy and, urged to

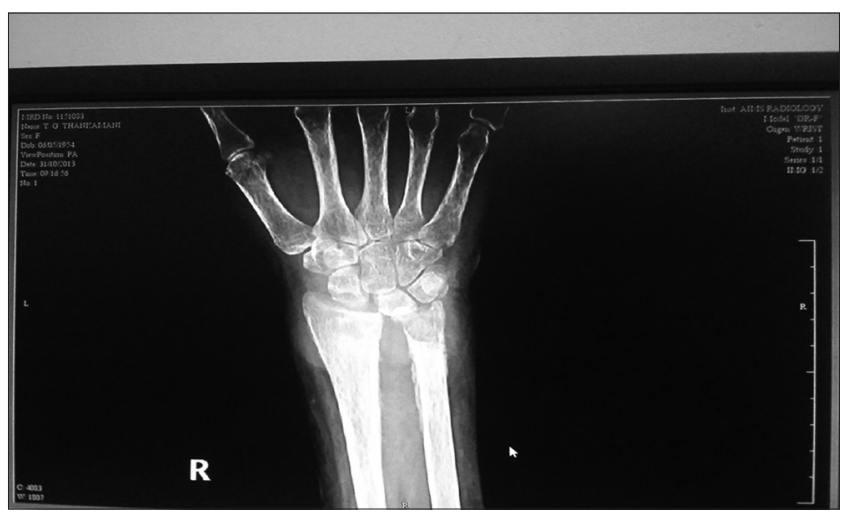

Fig. 1: X-ray (right wrist joint)

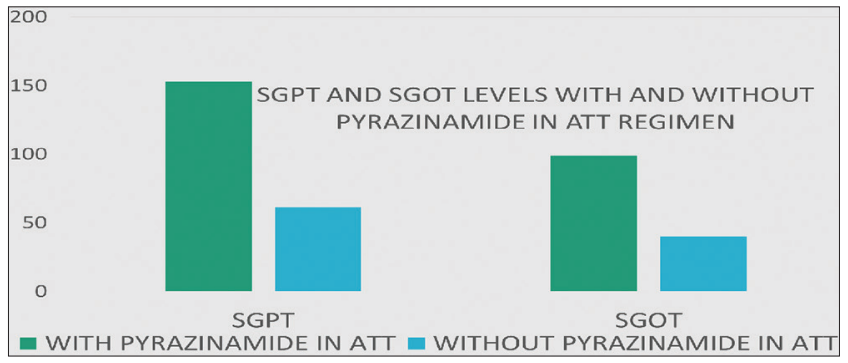

Fig. 2: Graphical representation of serum glutamate-pyruvate transaminase and serum glutamic oxaloacetic transaminase levels with and without pyrazinamide in anti-tuberculosis treatment regimen

report and consult physician/pharmacists on persisting symptoms if any. TB arthritis and hepatotoxicity can prolong the hospital stay or may result in readmission, thus contributing to increase in morbidity, mortality, and total cost for the hospitalized patient. The recognition of risk factors, monitoring for clinical course and laboratory results and patient education might be able to prevent such events.

\section{ACKNOWLEDGMENT}

We thank the Almighty and our parents for channeling our strength and courage so as to aspire our aims.

\section{REFERENCES}

1. Osonwa UE, Ugochukwu JI, Onyegbule FA, Esimone CO. Pharmacokinetics, hematologgical and biochemical effects of ciprofloxacin hydrochloride-sodium cholate complex. Int J Pharm 
Pharm Sci 2016;8(10):96-101

2. Sciberras NC, Lindsay JR. A rare presentation of TB: Osteomyelitis of distal ulna. J Surg Case Rep 2011;2011(1):4.

3. Bodelier AG, Masclee AA, Bakker JA, Hameeteman WH, Pierik MJ. Azathioprine induced pneumonitis in a patient with ulcerative colitis. J Crohns Colitis 2009;3(4):309-12.

4. Raghu G, Collard HR, Egan JJ, Martinez FJ, Behr J, Brown KK, et al. An official ATS/ERS/JRS/ALAT statement: Idiopathic pulmonary fibrosis: Evidence-based guidelines for diagnosis and management. Am J Respir Crit Care Med 2011;183(6):788-824

5. Orlicka K, Barnes E, Culver EL. Prevention of infection caused by immunosuppressive drugs in gastroenterology. Ther Adv Chronic Dis 2013;4(4):167-85

6. Beck JS, Lowe JG, Grange JM. Corticosteroids as a risk factor for tuberculosis. Tuber Lung Dis 1993;74(6):413-4.

7. Shaji J, Shaikh M. Drug resistant tuberculosis: Recent approach in polymer based nanomedicine. Int J Pharm Pharm Sci 2016;8(3):1-6.
8. Waitt CJ, Squire SB. A systematic review of risk factors for death in adults during and after tuberculosis treatment. Int J Tuberc Lung Dis 2011;15(7):871-85.

9. Kishore PV, Palaian S, Paudel R, Mishra P, Prabhu M, Shankar PR. Drug induced hepatitis with anti-tubercular chemotherapy: Challenges and difficulties in treatment. Kathmandu Univ Med J (KUMJ) 2007;5(2):256-60.

10. Suthar AM, Patel VV. Suspension of isoniazid formulated using cationic resin for pediatric use. Int J Curr Pharm Res 2017;6(2):42-6.

11. Sukhithasri V, Vinod V, Varma S, Biswas R. Mycobacterium tuberculosis treatment modalities and recent insights. Curr Drug Deliv 2014;11(6):744-52.

12. Singh JA, Saag KG, Bridges SL Jr, Elie AA, Bannuru RR, Sullivan MC, et al. 2015 American college of rheumatology guideline for the treatment of rheumatoid arthritis. Arthritis Care Res 2015. DOI: $10.1002 /$ acr. 22783 